\title{
Benign myoclonic epilepsy in infancy: neuropsychological and behavioural outcome
}

\author{
Salvatore Mangano*, Antonina Fontana, Liberia Cusumano \\ Dipartimento Materno Infantile, Unità di Neuropsichiatria Infantile, Università di Palermo, via Lancia di Brolo 10 bis, 90145 Palermo, Italy
}

Received 26 June 2003; received in revised form 22 April 2004; accepted 26 April 2004

\begin{abstract}
Benign myoclonic epilepsy in infancy (BMEI) is a rare syndrome of idiopathic generalized epilepsies with onset below 3 years of age. It has been reported that BMEI is associated with a good prognosis, however, recently some studies suggest less favourable neuropsychological outcome. We report a long-term follow-up of seven patients with BMEI. Seizure outcome and neuropsychological, cognitive, and behavioural evolution were discussed for each of them. At the end of follow-up, $86 \%$ of children showed neuropsychological and intellectual disorders: two children had mental retardation, three patients achieved a borderline IQ and one normal but low IQ. All but one displayed neuropsychological disabilities including fine motor skill deficits, attention deficits, and language impairment and learning disorders. Our clinical data and the previous reports suggest that the early onset of the seizures may be one of the main factors of the illness giving rise to a less favourable outcome. Additional interacting factors such as delayed start of treatment, and efficacy of the drugs may play an important role, too. We believe that BMEI does not exert, different from some epileptic encephalopathies, a quick destroying effect but may interfere with the growth of developing functions, which results in long-term neuropsychological disabilities.
\end{abstract}

(C) 2004 Elsevier B.V. All rights reserved.

Keywords: Benign myoclonic epilepsy in infancy; Neuropsychological outcome; Behavioural outcome; Onset age

\section{Introduction}

Benign myoclonic epilepsy in infancy (BMEI), delineated by Dravet and Bureau in 1981 [1], is a rare syndrome of idiopathic generalized epilepsies (IGE) with onset below 3 years of age. There is a prevalence of males with a ratio of approximately $2-1$. About $30 \%$ of affected children has a family history of epilepsy or febrile convulsions (FC).

The seizures occur in healthy infants, and are characterized by brief generalized myoclonic jerks involving the axis of the body and limbs. They usually last $1-3 \mathrm{~s}$ and are isolated, although sometimes they occur in cluster. BMEI is never associated with other seizure types, but rare FC may precede or follow the onset of myoclonic attacks.

Ictal EEG shows brief generalized $3 \mathrm{~Hz}$ spike-wave (SW) or polyspike-wave (PSW) discharges increasing during drowsiness. Seizures are well controlled by sodium

\footnotetext{
* Corresponding author. Tel./fax: +39-91-682-0282.

E-mail address: manganos@katamail.com (S. Mangano).
}

valproate (VPA) but relapses have been reported in few patients later in adolescence requiring reintroduction of the drug [2]. Although BMEI prognosis has been considered favourable, some studies suggest a less favourable neuropsychological outcome [2-5].

The disagreement on long-term outcome of BMEI induced us to investigate the seizure-associated factors that may be involved in cognitive and behavioural development. We report a long-term follow-up of seven patients with BMEI. Seizure outcome and neuropsychological, cognitive, and behavioural evolution were discussed.

\section{Patients and methods}

Seven children (three males and four females) with a mean age of 8 years 1 month (range: 5 years 8 months-10 years 2 months) were enrolled among 1110 epileptic patients who were referred to the Child Neuropsychiatry Clinic of University of Palermo between January 1992 
and December 2002. To be included in this study, patients were required to have a diagnosis of BMEI according to the criteria reported by the Classification of Epilepsies and Epileptic Syndromes [6], normal developmental milestones at first hospital admission, and lack of markers suggesting a pre-existing encephalopathy. The average duration of the follow-up was 6 years 9 months (range: 4 years 9 months -9 years 2 months). We investigated the following data: (a) family history, personal past history and postnatal troubles; (b) psychomotor development; (c) neurological examination; (d) brain CT scan; (e) age at onset of myoclonic seizures (MS); (f) clinical and EEG features of seizures; (g) antiepileptic treatment; (h) interval between seizure onset and starting antiepileptic drugs (AED); (i) seizure and EEG evolution; (j) long-term neuropsychological, cognitive, and behavioural outcome.

Neuropsychological profiles were constructed on the basis of different tests, depending on the characteristics of each patient. The Brunet-Lézine scale was used to assess the psychomotor development. The Wechsler Preschool and Primary Scale of Intelligence (WPPSI) and the Wechsler Intelligence Scale for Children-Revised (WISC-R) were administered to determine verbal and performance IQ. We used the Bender Visual Motor Gestalt Test (BVMGT as scored by Santucci for Italian sample) to measure visualmotor integration and the oral language test (TVLO as scored by Ferrari et al. for Italian sample) to assess language abilities. Recalling sentences (RS) and spontaneous speech (SS) subtests were used to assess expressive syntax. The token test (TT) and visual naming (VN) subtests were used to measure receptive syntax and vocabulary.

Although no behavioural questionnaire was administered, we paid close attention to possible emotional or behavioural problems (such as anxiety, shyness, hyperactivity, aggressiveness, irritability, oppositional conduct, and attention problems) during clinical follow-up. Informations were obtained by parent and teacher interviews and by clinical observations.

\section{Results}

Clinical data of our patients are reported in Table 1. Four patients (57\%) had a family history of epilepsy and FC. No patient had notable past history and postnatal troubles. Three infants experienced FC before onset of MS. At the first hospital admission, findings of neurological examination and psychomotor development were normal in all patients. Brain computed tomography scan in two patients (cases 1 and 2) did not show any abnormality. Mean age at onset of MS was 15 months (range: 7 months -35 months). Myoclonic jerks occurred at 7 months of age in two children (29\%), between 11 and 14 months in three patients (43\%), at 22 and 35 months in two patients (29\%), respectively. The seizures were characterized by myoclonic jerks involving mainly the upper limbs in all patients, and in some cases they provoked nodding with upward gaze deviation, bending of the body axis and flexing or reduction of tone in the lower limbs. MS occurred many times a day and were never associated with other seizures. Ictal EEG recordings showed generalized SW and/or PSW discharges synchronous with myoclonus (Fig. 1), and interictal EEG showed no abnormalities (Fig. 2). Two children (29\%) had myoclonus triggered by tactile or acoustic stimuli. VPA was effective in all patients but one who needed clobazam add-on. The average interval between seizure onset and VPA administration was 2 months 15 days (range: 18 days-5 months). The patients became seizure-free within a mean period of 7 months 15 days (range: 10 days-28 months) with disappearance of generalized SW and/or PSW discharges

Table 1

Benign myoclonic epilepsy in infancy: clinical characteristics

\begin{tabular}{|c|c|c|c|c|c|c|c|c|c|c|}
\hline $\begin{array}{l}\text { No. } \\
\text { pat. }\end{array}$ & Sex & $\begin{array}{l}\text { Family } \\
\text { history }\end{array}$ & $\begin{array}{l}\text { FC before } \\
\text { MS start }\end{array}$ & $\begin{array}{l}\text { Age at } \\
\text { MS onset }\end{array}$ & $\begin{array}{l}\text { Age/ } \\
\text { psychomotor } \\
\text { development } \\
\text { at first hospital } \\
\text { admission }\end{array}$ & AED & $\begin{array}{l}\text { Interval } \\
\text { between } \\
\text { MS onset } \\
\text { and start } \\
\text { of AED }\end{array}$ & $\begin{array}{l}\text { Interval } \\
\text { between } \\
\text { start of AED } \\
\text { and seizure } \\
\text { control }\end{array}$ & $\begin{array}{l}\text { Age at } \\
\text { seizure } \\
\text { control }\end{array}$ & $\begin{array}{l}\text { Duration } \\
\text { of follow-up }\end{array}$ \\
\hline 1 & F & - & - & 7 months & $\begin{array}{l}9 \text { months/ } \\
\text { normal }\end{array}$ & $\begin{array}{l}\text { VPA+ } \\
\text { CLB }\end{array}$ & 2 months & 28 months & 37 months & $\begin{array}{l}7 \text { years } \\
7 \text { months }\end{array}$ \\
\hline 2 & F & $\mathrm{FC}$ & + & 7 months & $\begin{array}{l}11 \text { months/ } \\
\text { normal }\end{array}$ & VPA & 4 months & 10 days & 11 months & $\begin{array}{l}4 \text { years } \\
9 \text { months }\end{array}$ \\
\hline 3 & M & EPI & - & 11 months & $\begin{array}{l}15 \text { months/ } \\
\text { normal }\end{array}$ & VPA & 5 months & 6 months & 22 months & $\begin{array}{l}7 \text { years } \\
6 \text { months }\end{array}$ \\
\hline 4 & M & - & + & 12 months & $\begin{array}{l}12 \text { months/ } \\
\text { normal }\end{array}$ & VPA & 18 days & 3 months & 16 months & $\begin{array}{l}9 \text { years } \\
2 \text { months }\end{array}$ \\
\hline 5 & F & - & - & 14 months & $\begin{array}{l}15 \text { months/ } \\
\text { normal }\end{array}$ & VPA & 1 month & 6 months & 21 months & $\begin{array}{l}7 \text { years } \\
2 \text { months }\end{array}$ \\
\hline 6 & M & $\mathrm{FC}$ & + & 22 months & $\begin{array}{l}22 \text { months/ } \\
\text { normal }\end{array}$ & VPA & 1 month & 4 months & 27 months & $\begin{array}{l}5 \text { years } \\
2 \text { months }\end{array}$ \\
\hline 7 & F & EPI & - & 35 months & $\begin{array}{l}36 \text { months/ } \\
\text { normal }\end{array}$ & VPA & 2 months & 1 month & 38 months & $\begin{array}{l}6 \text { years } \\
2 \text { months }\end{array}$ \\
\hline
\end{tabular}

FC, febrile convulsions; EPI, epilepsy; MS, myoclonic seizures; AED, antiepileptic drug; VPA, valproic acid; CLB, clobazam. 


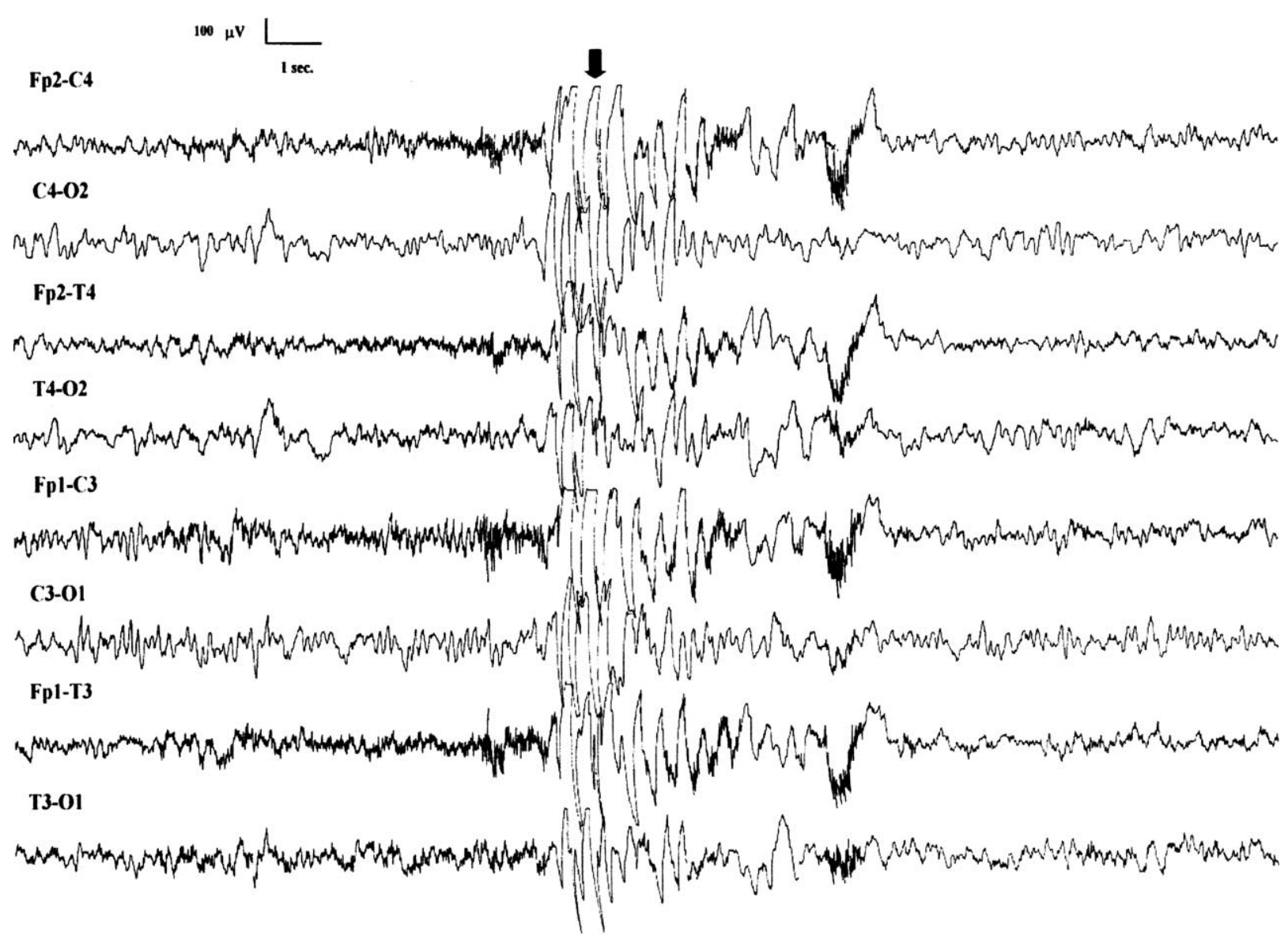

Fig. 1. Patient 2: the ictal EEG shows $\sim 3 \mathrm{~Hz}$ generalized high-amplitude spike and wave discharges synchronous with bilateral arm myoclonias.

in all but one showing EEG abnormalities until 3 years of age. All patients withdrew AED after a seizure-free period of 3 years. During the follow-up, relapses were not observed. At the end of follow-up (Table 2), two children had mild and moderate mental retardation, respectively, and showed other neuropsychological disorders: fine motor skill deficits, attention deficits and language impairment. In these patients the onset of MS was below 1 year of age and they were the youngest (age: 7 months) of our cases. Three children achieved a borderline IQ and one normal but low IQ. They displayed neuropsychological disabilities including learning disorders and attention deficits. Only one patient showed normal IQ without neuropsychological and behavioural problems.

The neuropsychological assessments during the followup allow us to draw some developmental outline (Table 2). At first assessment $\left(\mathrm{T}_{1}\right)$ all but one child had a normal developmental quotient (DQ). The evaluation of the child with a low DQ was performed 21 months after onset of MS. At second assessment $\left(T_{2}\right)$, after a mean period of 3 years from onset of seizures, two patients were mentally retarded, one child showed a borderline IQ, and four subjects had a normal mental development but two in the lower normal range. The mean FSIQ of the group as a whole was 78.6.
All children revealed oppositional conduct, irritability, aggressiveness and hyperkinesia.

At the end of follow-up $\left(\mathrm{T}_{3}\right)$, there was no change among FSIQ. The mean FSIQ of the group as a whole was 74 . The individual neuropsychological profiles were even in all but one (case 2) with a significant higher verbal IQ score.

On TVLO two children failed in all subtests and met criteria for language impairment $(P=0.01)$; four patients showed deficits on two subtests (SR and TT) assessing expressive and receptive syntax. The visual-motor integration abilities were at very low level in two patients.

Overall the patients have tended to progress at a low rate but one has shown normal progress. In addition, five children fulfilled DSM IV criteria for attention deficit disorder. School achievement was poor in all but one and four cases showed learning disorders. The patients attend normal school but the two mentally retarded patients need a support teacher.

\section{Discussion}

The myoclonic epilepsies have been at the core of the discussion on infantile epilepsies for many years. Since MS characterize a broad spectrum of infantile epilepsies, seizure 

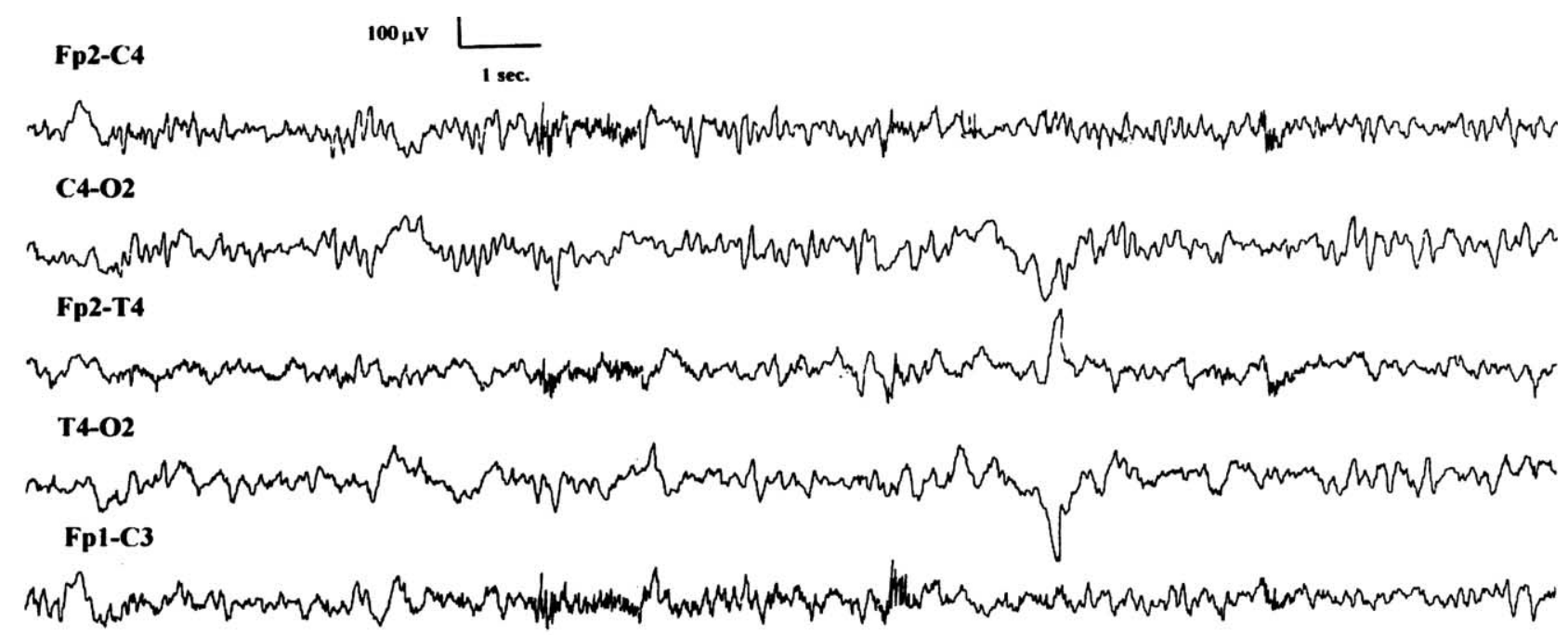
C3-01
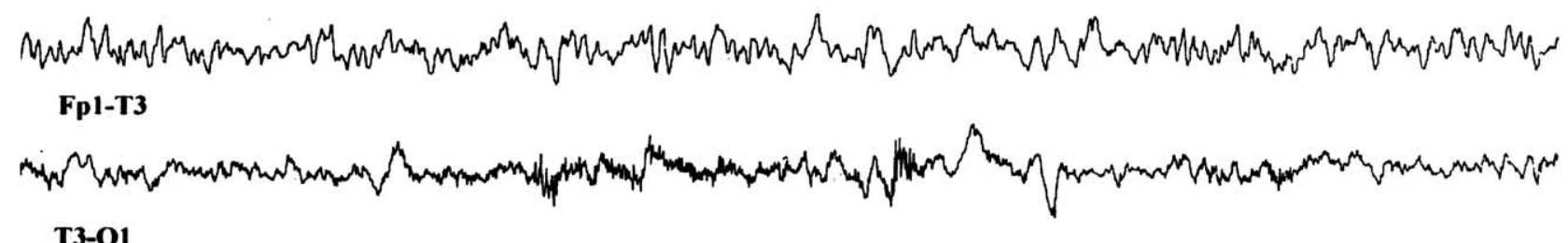

T3-01

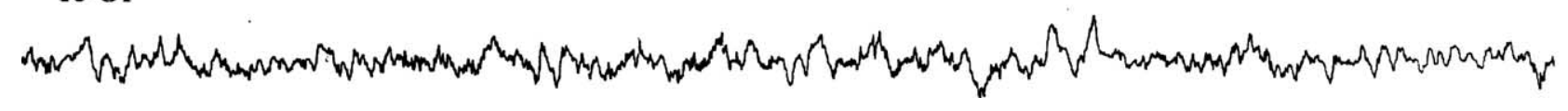

Fig. 2. Patient 2: the interictal EEG shows no abnormalities during wakefulness.

control and neuropsychological outcome may be different. The Commission on Classification of Epilepsies and Epileptic Syndromes has placed the BMEI, recognized by Dravet and Bureau [1], among the IGE starting before 3 years [6]. The clinical feature is characterized by MS, occurring in healthy infants between 4 and 36 months of age, and sensitive to appropriate antiepileptic treatment. The MS are associated with favourable prognosis and sometimes with FC during the course of disease.

The early reports have emphasized normal developmental milestones and lack of seizures after AED withdrawal in BMEI [7]. The few long-term follow-up studies have pointed out mental retardation, hyperkinesias, learning disabilities, attention deficit, or behavioural disorders [2-5]. The incidence of these findings has been $58 \%$ in Dravet's series, $21 \%$ in Todt's patients, $45 \%$ in Giovanardi Rossi's infants, and $10 \%$ in Lin's cases.

The high rate of these disorders makes the prognosis, previously defined, uncertain. Unfavourable cognitive and behavioural outcome has been reported to be related to early seizure onset, delayed start of treatment, personal history with pathological events, and disturbed mother-infant relationship [2].

Our results overlap with previous reports regarding clinical and EEG features including family history of FC or epilepsy, effective VPA treatment, interval between MS onset and starting AED, and seizure outcome.
At the end of follow-up, all but one of our children (86\%) showed less favourable neuropsychological and intellectual outcome than those previously reported by Giovanardi Rossi (45\%) and by Lin (10\%).

We believe that the reason for such a high rate of unfavourable outcome among our patients may be mainly, but not exclusively, related to the earlier onset of the seizures. In this study we enrolled children whose onset of MS was within 3 years of age while Giovanardi Rossi and Lin in their investigations included patients over 3 years of age, $3 / 11$ cases and $4 / 10$ cases, respectively.

In addition, MS onset within 14 months of age in $71 \%$ (5/7) of our patients, in 55\% (6/11) of Giovanardi Rossi's cases, and in no patient of Lin's subjects; and finally favourable outcome has been reported mainly in children whose age of MS onset was later [4,5, the present study], although this finding is not always significant in all investigations [4].

Nevertheless, in our patients, other additional interacting factors such as delayed start of treatment, efficacy of AED, and other unknown factors may have played a role in producing a less favourable outcome. In an another explanation, a pre-existing mild static encephalopathy or a minor brain dysfunction not detected by DQ test at this early age period may have been associated with BMEI predisposition, thus causing early onset MS, and later neuropsychological problems. Although DQ test scores 


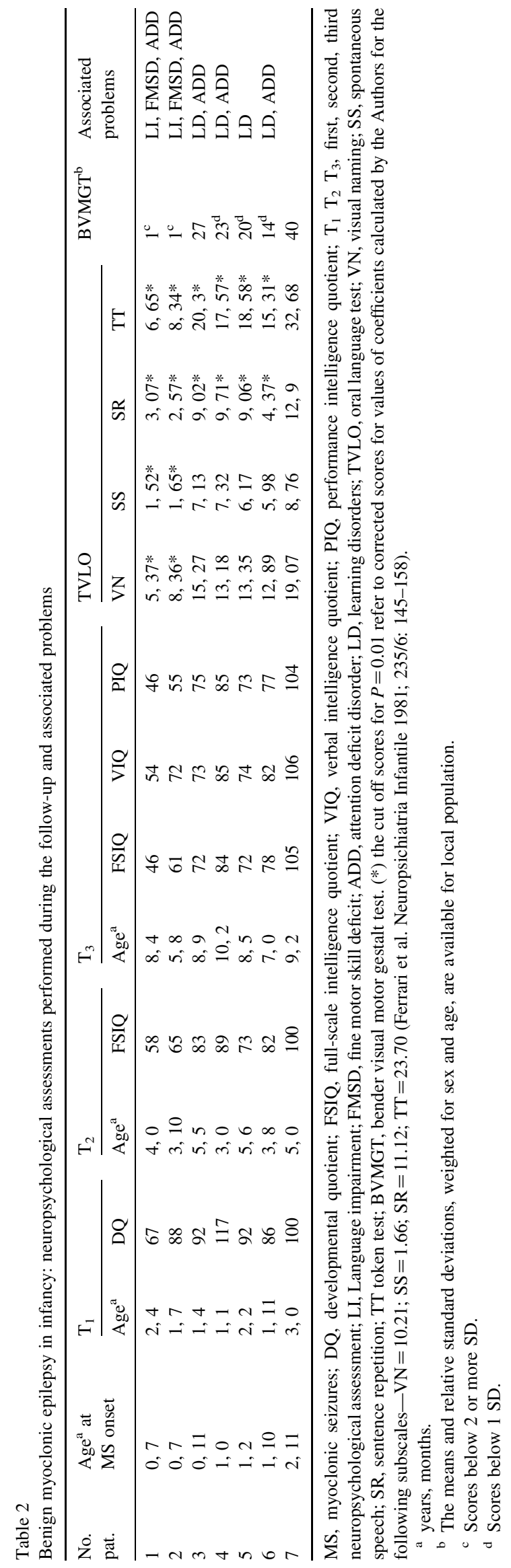

were within normal range in all but one patient who was measured 21 months after the onset of MS, DQ test has a limitation to reflect exact intelligence because it only measures a global developmental function. However, we believe that our patients did not reveal significant problems nearly at onset of the disorder because we carried out detailed neurological and developmental examinations in addition to DQ test during the first admission. We are conscious that our view may be not conclusive considering also the limited number of case studies up to now.

At the last examination, all children but two displayed a low intellectual performance (Table 2). The group as a whole showed a FSIQ below the population mean.

It is likely that BMEI does not exert, different from some epileptic encephalopathies, a quick destroying effect but interferes with the development of the growing functions, and results in long-term neuropsychological disabilities. Thus, the harmful effect of BMEI on basic cognitive processes may induce very serious consequences on a wider range of later abilities.

Whereas the immature brain does not show detectable seizure-induced cell loss than the mature brain [8-10], there is some evidence from animal studies that the neonatal recurrent seizures may produce significant and often irreversible alterations in the developing brain [11-13]. Following recurrent seizures during early development in rats, mossy fiber sprouting and increased expression of glutamate receptors in the hippocampus (CA3 and supragranular region of the dentate gyrus) are associated with increase in seizure susceptibility and long-term impaired visual-spatial learning and memory [11,14-16]. On the other hand, since most mossy fibers are connected with GABA inhibitory interneurons [17], it is unclear yet which of the anatomical changes are responsible for the cognitive impairment and the lower seizure threshold. In addition, unlike adult rats, recurrent neonatal seizures are associated with a remarkable decrease in neurogenesis of granule cells of the dentate gyrus [18]. The mechanisms by which early recurrent seizures result in cognitive impairment may be more complex involving also the sequential expression of receptors, and the formation and probably stabilization of synapses [19].

Although the extrapolation of animal experiments to the human condition is difficult, the seizure-induced brain changes at different stages of development may lead to different levels of neuropsychological dysfunction: the earlier MS occur, the greater the range of impaired cognitive abilities.

Our clinical data suggest that brain development may be more vulnerable to BMEI within 2 years of age than later age. After the seizure onset, our younger patients tend to achieve a defective neuropsychological profile that shows little changes over time. The seizure activity in the early stage of brain development could induce an abnormal arrangement of the underlying processes involved in 
the organization of the following complex cognitive abilities. In summary, it is likely that the developmental stage of the brain and the MS, interacting with other factors mentioned above, could account for the different degrees of neuropsychological dysfunctions found in patients with BMEI.

\section{Acknowledgements}

We are grateful to Mr Brinley Thomas for his assistance in checking the translation.

\section{References}

[1] Dravet C, Bureau M. The benign myoclonic epilepsy of infancy. Rev Electroencephalogr Neurophysiol Clin 1981;11:438-44.

[2] Dravet C, Bureau M, Roger J. Benign myoclonic epilepsy in infants. In: Roger J, Bureau M, Dravet C, Dreifuss FE, Perret A, Wolf P, editors. Epileptic sundromes in infancy, childhood and adolescence. Rome: Libbey; 1992, p. 67-74.

[3] Todt H, Muller D. The therapy of benign myoclonic epilepsy in infants. Epilepsy Res 1992;6:137-9.

[4] Giovanardi Rossi P, Parmeggiani A, Posar A, Santi A, Santucci M. Benign myoclonic epilepsy: long-term follow-up of 11 new cases. Brain Dev 1997;19:473-9.

[5] Lin Y, Itomi K, Takada H, Kuboda T, Okumura A, Aso K, et al. Benign myoclonic epilepsy in infants: video-EEG features and longterm follow-up. Neuropediatrics 1998;29:268-71.

[6] Commission on Classification and Terminology of the International League against Epilepsy. Proposal for revised classification of epilepsies and epileptic syndromes. Epilepsia 1989;30:359-99.

[7] Dravet C, Bureau M, Genton P. Benign myoclonic epilepsy of infancy: electroclinical symptomatology and differential diagnosis from other types of generalized epilepsy of infancy. Epilepsy Res 1996;Suppl 6:S131-S135.

[8] Holmes GL, Thompson JL, Marchi T, Feldman DS. Behavioral effects of kainic acid administration on the immature brain. Epilepsia 1988; 29:721-30.

[9] Stafstrom CE, Thompson JL, Holmes GL. Kainic acid seizures in the developing brain: status epilepticus and spontaneous recurrent seizures. Brain Res Dev Brain Res 1992;65:227-36.

[10] Hirsch E, Baram TZ, Snead 3rd OC. Ontogenic study of lithiumpilocarpine-induced status epilepticus in rats. Brain Res 1992;583: $120-6$.

[11] Holmes GL, Gairsa JL, Chevassus-Au-Louis N, Ben-Ari Y. Consequences of neonatal seizures in the rat: morphological and behavioral effects. Ann Neurol 1998;44:845-57.

[12] Huang LT, Cilio MR, Silveira DC, McCabe BK, Sogawa Y, Stafstrom CE, et al. Long-term effects of neonatal seizures: a behavioral, electrophysiological, and histological study. Brain Res Dev Brain Res 1999;118:99-107.

[13] Holmes GL. Seizure-induced neuronal injury. Animal data. Neurology 2002;59(suppl 5):S3-S6.

[14] Holmes GL, Sarkisian MR, Ben-Ari Y, Chevassus-An-Louis N. Mossy fiber sprouting after recurrent seizures during early development in rats. J Comp Neurol 1999;404:537-53.

[15] Liu X, Yang Y, Silveira DC, Sarkisian MR, Tandon P, Huang LT, et al. Consequences of recurrent seizures during early brain development. Neuroscience 1999;92:1443-54.

[16] Sogawa Y, Monokoshi M, Silveira DC, Cha BH, Cilio MR, McCabe BK, et al. Timing of cognitive deficits following neonatal seizures: relationship to histological changes in the hippocampus. Brain Res Dev Brain Res 2001;131:73-83

[17] Acsády L, Kamondi A, Sík A, Freund T, Buzsáki G. Gabaergic cells are the major postsynaptic targets of mossy fibers in the rat hippocampus. J Neurosci 1998;18:3386-403.

[18] McCabe BK, Silveira DC, Cilio MR, Cha BH, Liu X, Sogawa Y, et al. Reduced neurogenesis after neonatal seizures. J Neurosci 2001;21: 2094-103.

[19] Holmes GL, Ben-Ari Y. Seizures in the developing brain: perhaps not so benign after all. Neuron 1998;21:1231-4. 